\title{
Linguas en contacto e interferencias
}

\author{
Rafael Chacón Calvar
}

Profesor de IES

Préstamos e interferencias son termos usados para definilos tipos de intercambios que se poden producir entre as linguas, xa estean en contacto nun mesmo territorio ou non. Préstamo aparece como o termo máis neutro para definir un suposto intercambio máis ou menos igual, e o segundo, a interferencia, preséntase máis como una modificación ou «agresión» dunha lingua noutra. Supoñamos o campo conceptual habitáculo nunha lingua romance calquera, que pode ser descrito moi superficialmente así:

\begin{tabular}{|c|c|}
\hline \multicolumn{2}{|c|}{ HABITÁCULO } \\
\hline HUMANO & NON HUMANO \\
\hline CASA, CABANA, ...n & TOBO, GORIDA, ... n \\
\hline
\end{tabular}

Consideremos agora o termo «igloo» do esquimo, que en orixe aparece nestas linguas, polo que se pode dicir que nelas había en potencia unha lagoa léxica ou matricial que podería ser recheada pola importación de «igloo». Neste caso falariamos de préstamos, xa que unha lingua complementaría a outra. Pero a mesma noción de préstamo vólvese inútil xa que non hai intercambio, nin desigual ou igual, porque os préstamos nunca se devolven nin supoñen perda no doante. Por outra parte, considerar un termo ou grupo de termos de forma illada e consideralos como préstamos, que en principio pode parecer aceptable, é ignorar a situación en que tales préstamos se producen. É a totalidade dos «préstamos» a que define as posibles relacións das linguas en contacto. Os préstamos mutuos que o francés e o inglés se fan actualmente son, en canto a cantidade, maiores por parte do inglés, especialmente na linguaxe técnica. Sen embargo, os préstamos que o francés produciu no inglés medieval son unha cantidade abrumadoramente maior en beneficio do francés, que chegou a producir unha verdadeira dobre escala sinonímica segundo fose a 
orixe do termo e a súa distribución social ou cultural. A forma galega "parexa» no é simplemente un préstamos do castelán "pareja», xa que xunto a «parexa» subsiste o galego «parella», coa conseguinte restricción semántica do termo xenuíno galego. «Parexa» úsase para humanos (de noivos, da garda civil,...) e «parella» para animais. Isto obriga a explicar estes fenómenos dun xeito moi distinto de cómo se fai para explicar as relacións do francés e o galego nun bilingüe galego-francés. Se un falante galego produce no seu francés «Je veux manger pain» está calcando no francés unha estructura castelá e subestima unha distinción francesa, como é o partitivo (Je veux manger du pain). Pola contra cando un francófono produce en galego "Quero comer do pan» sobreestima no galego unha distinción que o francés fai e o galego non. Este tipo de fenómenos son caracterizadas como de interlinguaxe, moi distintos dos simples préstamos. A existencia de dunha lagoa léxica como mecanismo dos préstamos podería explicar en galego actual cousas como "tortilla", "bocadillo» ou "zarzuela» de procedencia castelá, pero non o calco dun partitivo nunha lingua que non o ten.

No caso dun bilingüe composto galego/castelán é evidente que no se poden cualificar como préstamos cousas como "parexa" por "parella», que non s6 se presenta como unha modificación fónica (a substitución do fonema castelán $/ \mathrm{X} /$ polo galego /s/, senón tamén léxica, que leva consigo a alteración dun subsistema particular.

Tampouco explicaría a existencia dunha lagoa léxica o cambio da serie de adverbios galegos «onte- hoxe- mañá» en «ayer-hoxe-mañá», esta última calco da serie castelá «ayer-hoy-mañana». O ser coincidentes as dúas series en canto a número de termos e refire, non debía producirse en galego ningunha ocasión para o préstamo, xa que non hai lagoa léxica ningunha. Pero o certo é que en moitos falantes o termo «onte» desaparece en beneficio de «ayer».

Existen, ademais de préstamo, outros termos que designan distintos modos de contacto entre linguas, como son os termos de substrato, adstrato ou superestrato. $O$ substrato ou os chamados trazos de substrato fan referencia ás influencias soterradas que unha lingua xa desaparecida deixa noutra, que se asenta, digámolo así, sobre a súa desaparición. Esta influencia actúa moito despois de recibida a herdanza, e moitos lingüistas explican por este misterioso proceder o paso das xordas a sonoras na linguas romances, botando man do que chaman a lenición céltica, sen chegar a explicar nunca o proceso completo.

O termo «adstrato" coincidiría co que antes aludimos como préstamo, pero ofrece a súas mesmas dificultades. O mesmo sucede con superestrato, que fai referencia á situación na que unha lingua de «cultura» se superpón a outra, cedéndolle termos e estructuras. Esta lingua de cultura pode ser historicamente anterior ou coetánea á lingua influída. Así o latín e o grego que, fundamentalmente, desde finais da Idade Media e o Renacemento, son a orixe dos innumerables cultismos dos léxicos poéticos, filos 6 ficos ou científicos europeos. Sen embargo, se examinamos moitos deles, veremos que, aínda que o étimo último sexa o latín ou o grego, o étimo próximo, en canto ás linguas 
peninsulares se refire, é o francés ou o inglés. $O$ termo «ideal», na súa acepción moderna de modelo desexable, non é en verdade un cultismo de orixe directa das linguas clásicas, senón que por primeira vez aparece acuñado en tal sentido no inglés, máis tarde no francés, e aínda máis tarde no castelán, que é de onde o toma o galego actual. É dicir, definir en galego «ideal» como cultismo, que é como o fan os diccionarios, académicos ou non, é simplemente ignorar que antes de que tal termo se produza en galego hai catro linguas implicadas no tal transporte, ás que chamar superestrato é dicir ben pouco.

Dificultades semellantes ofrecen outros termos como estranxeirismo (galicismo, anglicismo, castelanismo, etc.) ou barbarismo, que, por moi xerais, resultan $\sigma$ final ambiguos e o único que denotan $\varepsilon$ a procedencia, pero non a calidade da relación das linguas en contacto. Os anglicismos, xermanismos, etc., ¿como e cando entran nunha lingua? ¿Por que entran? ¿Cando son estranxeirismos e cando deixan de selo? ¿Define en linguística algo máis que a súa orixe dicir que fútbol é un anglicismo?

Os barbarismos son, en principio, faltas que un falante produce 6 falar unha lingua distinta da súa. Son, pois, as estratexias da aprendizaxe e a calidade da mesma, as que explicarían tales barbarismos.

As alteracións na entoación da frase e do ritmo propios do galego, a indistinción entre vocais pechadas e abertas, etc., son variacións que non só afectan á fala (competencia), senón que chegan desde os usos coloquiais ata o sistema (perfomance). $O$ mesmo sucede coa colocación asistemática dos pronomes átonos, o uso de tempos compostos, etc., que alteran a morfosintaxe. A substitución de "peite» por "peine», a construcción de dobretes como parexa/parella, etc. afectan á distribución do léxico galego.

\section{DEFINICIÓN DE INTERFERENCIA}

Con Van Oberverke diremos que a interferencia é «todo uso que leva consigo, en certo grao, trazos provenientes dunha lingua diferente e que van contra a norma lingüística» (V. Overbeke p. 110). Como tal é:

1. Un uso ou suceso que se produce entre dous procesos. A interferencia comeza afectando á mensaxe ata chegar 6 código.

2. E unha infracción da norma na lingua recipiendaria.

3. É debida a unha lingua estranxeira.

Parecidas explicación atopamos nas gramáticas xerativistas que consideran a interferencia como unha expresión non prevista no conxunto de regras que constituen unha lingua. En efecto, a frase «Ela tivo ayer un antoxo» (cast.: «Ella tuvo ayer un antojo»/gal.: «Ela tivo onte un antollo») $\varepsilon$ unha frase 
que non se pode deducir da gramática galega explícita, se tomámo-la interferencia como un resultado, que son aquelas que mostran unha certa regularidade e progreso no uso. As interferencias non poden ser explicadas desde unha soa gramática, e afectan non só a fala senón tamén 6 código. Neste senso, a interferencia no é un caso máis da agramaticalidade, como infracción dunha regra, senón un modo do cambio linguístico. Non son agramaticalidades producidas desde ou nunha lingua, senón por intersección de dúas linguas, e só poden explicarse desde as dúas gramáticas. $O$ castelán préstalle $\sigma$ galego dentro do territorio galego, pero a o galego a penas o fai no territorio do castelán. Fóra da área do galego non hai interlingua ni interferencia, senón préstamos ou calcos posibles (galeguismos no castelán).

\section{O MECANISMO DA INTERFERENCIA}

Chamaremos lingua $A$ a lingua orixe das interferencias e lingua $B$ a lingua na que se producen. Para explicar cómo se producen as interferencias, teremos que ter en conta:

1. A situación asimétrica nas relacións entre as dúas linguas, $\mathrm{A}$ e $\mathrm{B}, \mathrm{e}$ cómo é o contacto. A situación do castelán (lingua A) e do galego (lingua B) en Galicia fai que as estratexias de aprendizaxe ou de comunicación dun falante de $B$, sexan interferidas non só para «aprehender» o castelán, senón a súa propia lingua. Esta superposición de A sobre B defínese como diglosia, e maniféstase no coloquio como bilingüismo composto, non coordinado.

2. O parentesco lingüístico entre dúas linguas fai posible que un falante de $A$, en moitas ocasións, poida usa-la súa lingua e ser comprendido por un de $B$ que empregue a súa lingua.

3. O grao de bilingüismo dos falantes de A e de B. Asî un falante galego vai identificando pares $(a / b)$ no discurso e prodúcese unha situación interlingüística na que terán lugar as futuras interferencias. Recollamos un exemplo xa citado para o galego e o castelán:

\section{A Ella tuvo ayer un antojo \\ B Ela tivo onte un antollo \\ B/a Ela tuvo ayer un antoxo}

$B / a$ define a interlingua de interferencias de $A$ en $B . O$ falante de $B$ identifica pares sinónimos tuvo/tivo, ayer/onte, antojo/antollo $\rightarrow$ antoxo, no seu intento de achegar B a $A$, que é a lingua de prestixio no coloquio, para designar referencias idénticas entre cada un dos termos de cada par, e así crea un diasistema $\mathrm{A} / \mathrm{B}$, que se manifesta no coloquio en galego como B/a. Cando u diasistema así formado permite a permutación en tódolos contextos de pares 
$\mathrm{a} / \mathrm{b}$ a sinonimia de traducción é total e completa, o que pode significar a perda de b por a, por simple economía. Por exemplo, tivo por tuvo, onte por ayer. Este fenómeno vén axudado pola homonimia doutros pares como un/un (aínda que tal vez, un en galego sexa tónico), ademais da paronimia antojo/antollo que se resolve nunha forma híbrida como antoxo. Sen embargo, o que se traduce non son os significados, senón as referencias, de aí as perdas no sistema de B. A situación de traducción sería seguinte:

(A) $\mathrm{SgL}>\mathrm{Sg} 2$ (B) antojo antollo

referente $A$ antojo(A)/antollo(B)/antoxo (B/a) referente $B$

Vemos, pois, que a lagoa léxica non está, nas situacións diglósicas, na orixe deste fenómenos, senón que dita lagoa vén provocada pola sinonimia interlingüística que actúa como verdadeiro mecanismo do cambio, axudada pola homonimia e pola paronimia, cando non por outros fenómenos como a polisemia, a metáfora ou a metonimia.

Con todo, hai que dicir que no caso as interferencias léxicas posúen un alto grao de indeterminación, xa que nelas interveñen numeroso factores, como a chamada lei do mínimo esforzo (economía) que leva a aceptar unha mesma forma léxica, a máis simple, para as dúas linguas ou a aceptación do termo máis xeral en detrimento do de menor extensión (Cf. aldea/pueblo/ciudad en castelán por aldea/vila/cidade en galego que se resolve en pobo/cidade). Pero, polo contra, atopamos casos nos que o rendemento económico «barato» se neutraliza como a da creación de de dobletes do tipo parella/parexa, paloma/pomba e a conseguinte distribución léxica, parexa para humanos e parella para animais; paloma para a doméstica e pomba para a torcaz. Aínda así, hai que dicir que os dobletes funcionan no mundo urbano ou urbanizado, pero non no mundo rural.

\section{TIPOS DE INTERFERENCIAS}

As interferencias foron clasificadas de moi diversas maneiras, xa fose atendendo $\sigma$ nivel de análise (fónicas, gramaticais, léxicas), xa fose polo seu grao de integración e polo modo de penetración na lingua anfitriona (introducción de identidades (fonemas/morfemas) ou de secuencias (sintácticas/léxicas), polas condicións da propia interferencia (factores lingüísticos/factores extralinguísticas) ou pola longuísima aceptación de criterios como fai Van Oberveke (interferencias proceso/resultado); proactivas/retroactivas; que afectan $\sigma$ código/que afectan á mensaxe; que afectan a formas libres/que afectan a formas obrigatorias; segmental/suprasegmental; da primeira articulación/da segunda articulación; gramatical/lexica; interlingüística/extralingǘstica; denotativas/connotativas). No noso caso, aceptaremos un esquema proposto por Payrato (Payrató, Lluis: 
La Interferencia Lingüistica. Comentaris i exemples catalá-castellá.Ed. Curial, Barcelona, 1985), no que intenta dar unha clasificación que logo pode reinterpretarse segundo cada un dos casos anteriormente citados, pero que atende as condicións básicas e xerais das interferencias. Referirémonos sempre as interferencias do castelán no galego.

I. SUBESTIMACIÓN DUNHA DISTINCIÓN

É o caso da interferencia no en que hai dous ou máis termos ma lingua $B$ e un só na lingua A como modelo:

\begin{tabular}{|l|l|l|}
\hline$A$ & $A$ & A \\
\hline B & b1, b2, b3... & b \\
\hline
\end{tabular}

\section{a. Interferencias fónicas}

O galego fai diferencia fonolóxica entre vocais abertas e vocais pechadas: presa/presa; oso/oso. Nos neoflanates galegos esta distinción adoita perderse, segundo o esquema:

\begin{tabular}{|l|l|l|}
\hline $\mathrm{A}$ & $\mathrm{e}$ & $\mathrm{e}$ \\
\hline $\mathrm{B}$ & $\mathrm{e} / \mathrm{e}$ & $\mathrm{e}$ \\
\hline
\end{tabular}

\begin{tabular}{|l|l|l|}
\hline $\mathrm{A}$ & $\mathrm{O}$ & 0 \\
\hline $\mathrm{B}$ & $\mathrm{o} / \mathrm{o}$ & $\mathrm{O}$ \\
\hline
\end{tabular}

Así presa e presa pasan a presa, o oso/oso pasa as dúas a oso.

As palabras galegas unha, alguna e ninguha teñen o fonema $/ \mathrm{nh} /$ do que o castelán carece. Ás, veces algún neofalantes do galego reducem $/ \mathrm{nh} / \mathrm{a} / \mathrm{n} /$.

\begin{tabular}{|l|l|l|}
\hline A & alguna & alguna \\
\hline B & algunha & alguna \\
\hline
\end{tabular}




\section{b. Interferencias morfosintácticas}

O galego, como o portugués, posúe un infinitivo conxugado que inclúe desinencias personais propias das formas finitas: facer(eu), faceres (ti), facer(el/ela), facemros (nós), facerdes (vós), faceren (eles/elas). Por inluencia do castelán, que no posúe tal distinción, esta forma tende a perderse na fla coloquial:

\begin{tabular}{|l|l|l|}
\hline A & Para hacer esto & Para hacer esto \\
\hline B & Para facermos isto & Para facer isto \\
\hline
\end{tabular}

O mesmo podiamos dicir das fromas do pronome átono que en galego son te par ao obxecto directo e che para o inidirecto: Vinte na festa/ Deiche un libro. Por influencia do castelán estas dúas formas vense reducidas a unha, a coincidente co castelánn na fala dos neoflanates:

1

\begin{tabular}{|l|l|l|}
\hline $\mathrm{A}$ & $\mathrm{Te}$ & $\mathrm{Te}$ (teismo) \\
\hline $\mathrm{B}$ & $\mathrm{Te} / \mathrm{che}$ & Che (cheismo) \\
\hline
\end{tabular}

\begin{tabular}{|l|l|l|}
\hline A & Te di un libro & Deite un libro \\
\hline B & Deiche un libro & \\
\hline
\end{tabular}

\begin{tabular}{|l|l|l|}
\hline A & Te vi en la fiesta & Vinche na festa \\
\hline B & Vinte na festa & \\
\hline
\end{tabular}

\section{c. Interferencias léxicas}

Se o modelo castelán presenta un soa forma, as variantes galegas podense reducir no coloquio:

\begin{tabular}{|l|l|l|}
\hline A & cerrar & cerrar \\
\hline B & cerrar, choer, fechar, pechar & cerrar \\
\hline
\end{tabular}

\begin{tabular}{|l|l|l|}
\hline $\mathrm{A}$ & último & último \\
\hline $\mathrm{B}$ & último/derradeiro & último \\
\hline
\end{tabular}


Neste tipo de interferencias prodúcese unha igualación de campos semánticos no coincidentes e queda como único o termo galego máis xeral e abstracto e comunmente homónimo co correspondente castelán. Queda reducida a distinción entre fechar, choer, pechar e cerrar no termo xeral de cerrar, ou a distinción entre derradeiro (último dunha serie) e último. Como resposta a esta hipodiferenciación, pode producirse nalgún neofalantes do galego o caso contrario, é dicir, a escolla do termo máis concreto polo máis xeral.

\begin{tabular}{|l|l|l|}
\hline A & unir/uncir & unir/uncir \\
\hline B & unir/xoncer & xoncer \\
\hline
\end{tabular}

No que xoncer (poñer os bois ou as vacas 6 carro) elimina no galego falado a unir, perfectamente galego, pero que por ultracorrección séntese como castelanismo, $\mathrm{O}$ mesmo en: -

\begin{tabular}{|l|l|l|}
\hline A & libre/suelto & libre \\
\hline B & libre/ceibe & ceibe \\
\hline
\end{tabular}

No que ceibe, que é o termo máis concreto, elimina no gálego dos neofalantes a libre. Así ;Viva Galicia ceibe! e non ¡Viva Galicia libre!, sentido este último como castelanismo. Escóllese. por ultracorrección o termo que ten segundo o falante máis aparencia galega fronte o se sente como castelán, aínda que sexa tamén xenuinamente galego.

\section{SOBREESTIMACIÓN DUNHA DISTINCIÓN}

É o caso inverso do anterior. O modelo castelán presenta dous ou máis termos e o galego un só. O resultado é a implantación de distincións provenientes do castelán no galego.

\begin{tabular}{|l|l|l|}
\hline A & al, a2, a3 ... & al, a2, a3 .. \\
\hline B & b & bl, b2, b3 .. \\
\hline
\end{tabular}




\section{a. Interferencias tónicas}

A presencia en certas palabras do fonema $/ \mathrm{X} /$ no galego explicaría algúns dos casos da gheada en termos como ghueves, ghuevos, etc., que son calcos do castelán, fronte a outras palabras que conservan $o / g /$.

\begin{tabular}{|l|l|l|}
\hline $\mathrm{A}$ & {$[\mathrm{g} / \mathrm{X}]$} & {$[\mathrm{g} / \mathrm{X}]$} \\
\hline $\mathrm{B}$ & $\mathrm{G}$ & {$[\mathrm{g} / \mathrm{X}]$} \\
\hline
\end{tabular}

\section{b. Interferencias morfosintácticas}

O galego non usa os tempos compostos, pero a aparición esporádica na fla e na literatura destes tempos ven explicada por este mecanismos:

\begin{tabular}{|l|l|l|}
\hline A & dijera/hubiera dicho & A/B:houbera dicho dito \\
\hline B & dixera & \\
\hline
\end{tabular}

\section{c. Interferencias léxicas}

É unha amplaición do campo léxico pòr adición de termos procedentes do castelán.

\begin{tabular}{|l|l|l|}
\hline A & silbato/pito & A/B:silbato, chifre, pito \\
\hline B & chifre & \\
\hline
\end{tabular}

\begin{tabular}{|l|l|l|}
\hline A & horno/panadería & A/B: torno, panadería \\
\hline B & torno & \\
\hline
\end{tabular}


III. REINTERPRETACIÓN DUNHA DISTINCIÓN

Neste caso o que varía no son os termos en si, senón as relacións que mantiñan anteriormente. Se representamos por $\mathbf{R}$ calquera relación entre dous termos, o esquema sería:

\begin{tabular}{|l|l|l|}
\hline$A$ & AlR1a2 & B1R2b2 \\
\hline$B$ & B1R1b2 & \\
\hline
\end{tabular}

\section{a. Interferencias fónicas}

Non atopamos interferencias deste tipo.

b. Interferencias morfosintácticas

Tal vez as seguintes diistinción que se fan no galego por parte de neoflaantes repondan a este tipo de interferencia:

\begin{tabular}{|l|l|l|}
\hline A & $\begin{array}{l}\text { conté/tengo contado } \\
\text { (+acción acabada, } \\
\text { aspecto reitertivo) }\end{array}$ & $\begin{array}{l}\text { Contei/teño contado (con } \\
\text { valor de «he contado», + } \\
\text { acción acabada, - aspecto } \\
\text { reitertivo) }\end{array}$ \\
\hline B & $\begin{array}{l}\text { contei/teño contado } \\
\text { (+acción acabada, } \\
\text { aspecto reitertivo) }\end{array}$ & \\
\hline
\end{tabular}

\section{c. Interferencias léxicas}

A partir dunha interferencia fónica, o cambio do fonema 111 por $I x /$, como no caso de parella/parexa, prodúcese na interlingua $A / B$ unha sinonimia 
referencial entre o castelán pareja e o galego parella, que ten como resultado un novo termo "parexa» segundo a tan coñecida analoxía si jamón é xamón entonces pareja é parexa, e dá lugar a un doblete léxico, xa que parexa non logra substituír en tódolos campos a parella.

\begin{tabular}{|l|l|l|l|}
\hline A pareja & Non humano & A/B & Parella (non humano) \\
\cline { 2 - 2 } & Humano & & \\
\cline { 2 - 2 } B parella & Non humano & & Parexa (humano) \\
\cline { 2 - 4 } & Humano & & \\
\hline
\end{tabular}

Así temos «parella de bois», pero «parexa de noivos" ou «da garda civil». Existen dobletes parecidos en «manoxo» (de flores) «mollo» (palla); "xaula» (páxaros) / «gaiola» (trampa para paxaros); «clavixa» (aparato) / «chavella» (do carro, dunha porta); "paloma» (caseña) / "pomba» (torcaz); "cuchara» (pequena) / «culler» (grande e para animais); conexo (caseiro)/coenllo (do monte). En Fonsagrada, 6 parecer, «murir» refírese ós humanos e «morrer» ós animais. En xeral, cando estes dobletes funcionan, á parte da redistribución semántica senón que esta coincide con divisións máis ou menos precisas como humano/non humano, rural/non rural; grande/pequeno,... nas que o non humano, rural grande no sentido pexorativo son designados polo termo galego, mentres que humano, o urbano, o pequeno (refinado) son designados polos termos producto da interferencia, cando non polo termo castelán.

\section{SUBSTITUCION}

O termo castelán substitúe o galego coa cosneguintte perda.

\begin{tabular}{|l|l|l|}
\hline $\mathrm{A}$ & $\mathrm{a}$ & $\mathrm{A} / \mathrm{B}: \mathrm{a}$ \\
\hline $\mathrm{B}$ & $\mathrm{b}$ & \\
\hline
\end{tabular}

\section{a. Interferencias tónicas}

\begin{tabular}{|l|l|l|}
\hline $\mathrm{A}$ & $\mathrm{X} / \mathrm{A} / \mathrm{B}: / \mathrm{X} /$ \\
\hline $\mathrm{B}$ & $/ \mathrm{s} /$ & \\
\hline
\end{tabular}




\begin{tabular}{|l|l|l|}
\hline A & jueves & A/B: jueves \\
\hline B & xoves & \\
\hline
\end{tabular}

Son os casos de general (por xeneral), gigante (por xigante) ... castelanismos duros que se producen no coloquio.

\section{b. Interferencias morfosintácticas}

No galego é obrigatorio o uso do posesivo sen artigo; non así no castelán. Mi casa está en la aldeal A miña casa está na aldea- Frases como «Miña casa está na aldea» é pois unha interferencia relativamente frecuente en neofalantes.

\begin{tabular}{|l|l|l|}
\hline A & Mi casa & \multirow{2}{*}{ A/B: Miña casa } \\
\cline { 1 - 2 } & A miña casa & \\
\hline
\end{tabular}

\section{c. Interferencias léxicas}

Neste caso a sinonimia de traducción, axudada pala posible homonimia ou paronimia ou por ambas, é total e completa no coloquio producíndose a desaparición do termo galego.

\begin{tabular}{|l|l|l|}
\hline A & Ayer & A/B:ayer \\
\hline B & Onte & \\
\hline
\end{tabular}

\begin{tabular}{|l|l|l|}
\hline A & Peine & A/B: peine \\
\cline { 1 - 2 } & peite & \\
\hline
\end{tabular}

Hai, pois, unha transferencia de significantes entre A e B por coincidencia de referentes, ou por semellanza de significados. Son moi abundantes as interferencias deste tipo, simplemente pola presión do termo castelán como modelo. 
V. IMPORTACIÓN

É caso no que o castelán «cede» formas ó galego para encher un baldeiro ou ocupalo, simplemente.

\begin{tabular}{|l|l|l|}
\hline A & A/B:a \\
\cline { 1 - 2 } & 0 & \\
\hline
\end{tabular}

\section{a. Interferencias fónicas}

Tal vez sexa o caso da importación do fonema $/ X /$ no galegop, aínda que galego no hai oposición fonolóxica $\mathrm{g} / \mathrm{X}$ (do tipo ganas/janas), senón só contraste.

\section{b. Interferencias morfosintácticas}

É o caso da importación de tempos compostos como «hei dito, houbera dito, o haxa dito», que o galego xenuino non usa.

\section{c. Interferencias léxicas}

É o caso de palabras como «cuartilla», «bocadillo», «quiniela», "zarzuela», ... que en galego no existían e que se toman en "préstamo» do castelán por necesidades léxicas ou de lagoas léxicas. Tamén é o caso de gran parte dos chamados cultismos, que se acuñan primeiro no castelán, e de aí pasan 6 galego. Moitos cultismos, anglicismos ou galicismos non son verdadeiramente tales, senón castelanismos. Se tosen verdadeiros anglicismos causas como chelín, cheque, ou chaqueta serían xelín, xeque ou xaqueta, xa que o galego Isl reproduce con bastante fidelidade o inglés Isl e no sería necesario substituílo por Icl, o que demostra que veñen do castelán. $O$ mesmo con champán, apache, etc. do francés, que debían ser, se tosen verdadeiros galicismos, xampán, apaxe. 
VI. PERdas

Non atopamos neste apartado casos de interferencias tónicas (o galego non perde ningún fonema por interferencia do castelán) nin tampouco morfosintácticas.

O esquema sería:

\begin{tabular}{|l|l|l|}
\hline $\mathrm{A}$ & 0 & $\mathrm{~A} / \mathrm{B}: 0$ \\
\hline $\mathrm{B}$ & $\mathrm{B}$ & \\
\hline
\end{tabular}

Realmente este no é un caso estricto de interferencia senón de perdas de formas por arcaímso. Palabras como rousar, choer, estixar, etc. ou o pouco uso do infinitivo conxugado pódense perder por arcaísmo, pero curiosamente se perden cando no castelán non existen.

\section{AS ULTRACCORRECIÓNS OU HIPERFORMAS}

Adóitase distinguir entre cambios lingüisticos que se producen por riba da conciencia linguiistica do talante e aqueles que se producen por debaixo dese nivel. Entre os segundo podemos incluir as interferencias de A en B, ou hipoformas, e entre os primeiros as ultracorreccións ou hiperformas. Cando un talante galego di «O xueves fun 6 cine», está demostrando que a súa conciencia lingüistica está bastante relaxada respecto da norma ou modelo ideal, se é o que o ten. Pola contra cando un talante, ou escribente, de galego produce unha hiperforma, tal como confliuto (por conflicto) ou caraiter (por carácter) está dando un claro testemuño da conciencia ou necesidade dunha norma que define a súa producción como correcta, e neste caso ultracorrecta. Se Rosalia de Castro ou Lamas Carvajal, na segunda metade do XIX, usan formas como fortúa por fortuna, ou brilar por brillar, é porque queren reautentificar unha lingua que percibe como contaminada polo castelán. Se historicamente o latin luna dá lúa e gallu, galo, entonces fortuna debe ser fortúa e brillare, brilar. Sen embargo, a historia é outra moi distintas do que a conciencia lingüistica de Rosalia e Lamas quere. Brillar e fortuna son formas perfectamente correctas tanto en galego coma en castelán, xa que cando este termos entran no galego xa non funcionaban os mecanismos que facian de luna-> lúa ou gallu, galo. Rosalia e Lamas ultracorrixen a súa lingua para diferenciala do castelán, crendo que esas formas son as xenuinas galegas e fortuna e brillar, castelanismos rexeitables. Cren responder asi ás prédicas lingüisticas do gramático Saco y Arce, que denuncia nos poetas galegos 
formas castelanizadas, ou simplemente castelanismo, como cadena, llama, pino, conexo, lexos, aleixar..., e que, segundo o mesmo gramático, se non se atallan axiña, o galego converterase nunha estraña xerga que servirá de transición entre o galego e o idioma de Castela que aspira a reemprazalo $\left(^{* *}\right)$.

O mecanismo língüistico das hiperformas que se dan ó longo do XIX e do $\mathrm{XX}$ está sempre na sobrexeneralización dunha regra da lingua que só funcionou en certos casos e en certos momentos, pero que deixara de funcionar habia séculos. Convértese asi a propia lingua (native language) nunha lingua obxectivo (target language) e aplicase nela formas ideais para reautentificala e descontaminala da presión que o castelán exerceu sobre ela e que non unha evolución propia e libre. No é gratuito que as hiperformas aparezan coas prime iras gramáticas galegas. $O$ mesmo Saco e Arce produce cousas como hourizonte (por horizonte), adourar (por adorar) ou viútima (por victima) a pesar da súa forte preparación lingüistica. Curros produce entre outras leiga (lega), coseita (colleita), aneiga (anega, solaga), montana (montaña). É sen embargo, no primeiro tercio do século XX, a partir da creación das Irmandades da Fala e no seu periódico A NOSA TERRA, cando, no afán de recuperación lingüistica aparecen verdadeiros aluvións de hipergaleguismos, especialmente no cultismos. Por exemplo:

LATÍN

Grupo -CT-

actu sectione structura victima edictu

Grupo - CCoccidente

Grupo $-\mathrm{CN}-$

técnica

Grupo-CL-

spectaculu eispeutacro

Grupo L + cons

altu

altivo

ULTRACORRECIÓN EN GALEGO

FORMA CORRECTA

auto

aito, aitualidá

seizón, seición

estruitura, eistrutura, estroitura

viútima

ediuto

oucidente, oucidental

téinica, téunica

outivo acto, actualidade

sección

estructura

víctima

edicto

occidente, occidental

técnica

espectáculo

alto

altivo 
$-\mathrm{i}-$

$\begin{array}{lll}\text { traiectoria } & \text { traieutoria, trayeutoria } & \text { traxectoria } \\ \text { proiectu } & \text { proieito, proyeuto } & \text { proxecto }\end{array}$

Convén sinalar que solución como autualidá, seución, oucidental, téunica, astrauto, proieuto, etc. no son vuIgarismos ou ultracorrección como algunhas gramáticas din, senón solucións semicultas de termos latinos en bocas de xuristas ou eclesiásticos. Desde antigo temos estas solución en galego, doutor, doutrina,...

\section{LUGAR DAS INTERFERENCIAS E DAS ULTRACORECCIONS NOS NIVEIS DE LINGUA}

Nunha lingua de difusión normal o nivel estándar, usado polas capas medianamente cultivadas, é a grandes trazos a lingua correcta, ou tida como tal. gen embargo, o problema do galego para a creación dese estándar é encher espacios interferidos na lingua talada. Por exemplo, as prazas correspondentes a lexías como selo, meixela, xeonllo ou oitenta poden estar ocupadas no coloquio por formas tomadas do castelán como sello, mexilla, rodilla ou ochenta. Na tala culta pódense ato par lagoas, xa o galego no creaba cultismos, senón que so tomaba prestados do castelán. Na tala cotiá no hai tales lagoas de feito ou o talante no ten conciencia delas, polo que o referente de selo poderá expresarse co castelanismo sello debido á esca tradición do estándar.

López del Castillo (*) propón o seguinte esquema para os niveis lingüísticos dunha lingua de difusión interferida:

NIVEIS:

ultracorreccións CULTO

préstamos

NORMATIVO
ESTANDAR
COLOQUIAL Interferencias
GALEGO
CASTELANIZADO
XERGAS
ARGOTS

no que as ultracorrección e os préstamos prodúcense, como reacción compensatoria, nos niveis cultos, xa que as ultracorreccións, hiperformas, hipergaleguismos ou hiperenxebrismos como se lles queira chamar, son sempre unha esaxeración da norma ou do uso. Pola contra, as interferencias prodúcense no nivel coloquial, para logo estenderse e acadar niveis máis altos, sobre todo cando a conciencia linguíistica (lealdade) é escasa. 


\section{INTERFERENCIAS E INTREGRACIÓN. ESTRANXEIRISMOS}

Se as interferencias máis persistentes se xeneralizan, a interferencia pasa de ser un proceso a ser un resultado, en termos de Van Oberveke. Esta progresión é unha gramaticalización ou lexicalización da interferencia dentro do sistema da lingua interferida. Varios son os factores que favorecen a difusión e a integración da interferencia. En primeiro lugar, o seu grao de adaptabilidade fónica, morfosintáctico, léxico ou gráfico. Así a homonimia interlinguística fai que nalgún momento o falante no teña conciencia de cál é o termo propio e cál - alleo. O galego libre e o castelán libre preséntanse como homónimos e sinónimos interlingüísticos perfectos, e nada pasaría se en galego no houbese a oposición libre/ceibe, que pode deixar de funcionar en beneficio do termo máis xeral (e coincidente con castelán) libre. Pola contra, por diferencialismo, pode suceder que ceibe ocupe espacios de libre, para fuxir de libre como posible castelanismo. Así, ¡Viva Galicia ceibe! e non ¡Viva Galicia libre!

Outro dos factores de integración é a sinonimia interlinguística ou de traducción, pois o que se traduce, máis que significados, son referencias. Así galego berce/castelán cuna resólvese en cuna axudada polo perfecto grao de adaptabilidade de cuna, xa que tódolos seus fonemas do castelán existen en galego.

$O$ único factor que importa no préstamo fónico e o sistema fonoléxico da lingua receptora. Os fonemas dunha lingua dada poden ser tomados por outras linguas de forma diferente. Así o castelán IXI é tomado polo portugués como $\mathrm{Ig} /, \sigma$ carecer este do fonema IX/.

cast. carajo port. carago

Pero non sucede así en galego, no que, ademais da proximidade da geada, no que pareja non imitado como *parega, senón como parexa, e detrimento de parella. A analoxía e a súa frecuencia de uso fai posible a extensión da interferencia, en especial o tipo que acabamos de citar, dado o excelente rendemento de IXI > Isl como axente da interferencia.

Pero non so os sistemas fonoloxicos son os que importan, senon que as condicións fonéticas teñen un papel importante, xa que moitas formas poden explicarse como simple adaptación fónica:

stop estop squí esquí

A inserción dun lel pode explicarse por restriccións fónicas da lingua receptora. gen embargo, haberá que buscar outros factores, non só lingüísticos, para explicar plurais como clubs ou récords, non explicables por adaptación fónica.

(poñer aquí as solucións portuguesas dos estranxeirismos) Ninguén dubida que tortilla, quiniela ou zarzuela son verdadeiros préstamos do castelán no galego, xa porque saturan unha lagoa léxica, xa que pque a polisemia de ambos termos nos seus respectivos idiomas fan posible a transferencia: 


\section{A a1 a2 a3 a4 a5 \\ B b1 b2 b3 b4 b5}

Entón A por B. Por exemplo: A bocadillo $(1,2,3, \mathrm{n}) \mathrm{B}$ bocadiño $(1,23, \mathrm{n}) \mathrm{a} 2=\mathrm{b} 2$

Entonces bocadillo por bocadiño. (???) tortiña tortilla

Neste casos prodúcese un aumento ou unha restricción do significado do termo prestado. Aumenta cando o neoloxismo é o termo máis xeral e o termo xenuíno queda na súa posición ou reduce o seu significado. Cando sucede isto, poucas veces o termo importado é o xenuíno poden ser considerados sinónimos na situación resultante: (gol/tanto; bacon/touciño)

Así temos que son posibles na fala cousas como: bocadillo de lomo (calco do castelán) bocadiño de lomo (galego bocadiño (bocado pequeno) e castelán lomo). Pero non bocadiño de lombo.

Sen embargo, nos diccionarios de uso ou normativos termos palabras como xefe ou xardín danse como préstamos do francés. Tanto chef como jardin entran no castelán antes do século XV, e polo tanto as palatais casteláns /s/ e $/ z /$ ( $x$ e 9 ou j na escrita) reproducían con bastante fidelidade as francesas ( $n$ a escrita ch ou g/j). Así no castelán xefe (ou gefe ou jefe) do francés chef En como /s/ castelán dará $/ \mathrm{X} /$, entón jefe (xa co son fricativo). Parecido proceso que xardín ou xefe se deron no galego, salvo a última solución de $/ X /$ (fricativo) que o galego no ten. En galego moderno xa no se produce este tipo de adaptación. a francés bijouterie pasa 6 castelán como bisutería e de aquí 6 galego, no que tamén é bisutería (As Nomig xa dan bixutería). Se fose un préstamo directo do francés tería que se bixutería, xa que o galego mantén o fonema / $/$ /. a mesmo sucede como pigeon $\rightarrow$ pichón, e non *pixón, ou beige $\rightarrow$ beis, e non *beixe. Bechamel non é *bexamel, senón besamel ou bechamel, o mesmo que apache non é *apaxe, senón apache (Les Apaches de Belville, famosa banda de foraxidos/baile apache). En anglicismos como champú de shampoo, e non *xampú, chelín e non xelín (ver VOLGA).

Temos, pois, que unha gran parte dos chamados galicismo, anglicismos ou préstamos doutras linguas, non son tales senón que o son a través do castelán, que aporta o termo e tamén a súa adaptación fónica que o galego acepta (por castelanismo latente).

O mesmo sucede con escasos arabismo do galego, que en realidade son a súa meirande parte castelanismos. Albarán, albergue, alcoba, aldea, alcohol ou alcol, etc. veñen do castelán e non directamente do árabe, co que nunca houbo contactos. Alfaia ou alfán- dega conservan aínda o f- inicial castelán, que logo pasa a h e a o. Así alhaja ou alhóndiga.

A interferencia morfosintáctica é un cambio de regra, dunha transformación obrigatoria ou facultativa, cambio de propiedades dalgún elemento ou grupo sintáctico que fai cambien a información esperada. $O$ cambio de xénero dalgunhas palabras como sal, mel, fel ou o cambio de rección dos verbos (vou a 
ir por vou ir) fai que se produzan frase do tipo Vou a comprar a mel por vou comprar o mel.

A interferencia, una vez integrada, debe ser considerada coma un producto dun cambio condicionado desde a estructura doutra lingua. Se hai moitas interferencias, a tendencia pode parecer que ir cara un pidgin (abandono de oposicións, xeralización de membros non marcados, conversión dunha transformación opcional nunha obrigatoria, eliminación de categorías, substitucións...). Se embargo a tendencia ó pidgin é sempre unha simplificación, e aínda que haxa coincidencia entre algúns mecanismos da interferencia e os dos pidgin, no caso das interferencias galegas, atopamos no só simplificación, senón tamén de ampliación (dobletes, sobreestimación de distincións, redistribución de distincións...) o que nos afasta do pidgin. É dicir, quizais esteamos no caso dunha substitución dunha lingua por outra, pero no de creoulización ou pidginización. 